\title{
Role of fried foods and oral/pharyngeal and oesophageal cancers
}

\author{
C Galeone ${ }^{*, 1}$, C Pelucchi', R Talamini' ${ }^{2}$ F Levi ${ }^{3}$, C Bosetti', E Negri', S Franceschi ${ }^{4}$ and C La Vecchia ${ }^{1,5}$ \\ 'Istituto di Ricerche Farmacologiche 'Mario Negri', Via Eritrea 62, 20157 Milan, Italy; ${ }^{2}$ Senvizio di Epidemiologia e Biostatistica, Centro di Riferimento \\ Oncologico, Via Pedemontana Occ.le, 3308 I Aviano (Pordenone), Italy; ${ }^{3}$ Registre vaudois des tumeurs, Institut universitarie de médicine sociale et \\ préventive, CHUV-Falaises I, 1011 Lausanne, Switzerland; ${ }^{4}$ International Agency for Research on Cancer, 150 COURS Albert Thomas, F-69372 Lyon, \\ cedex 08, France; ${ }^{5}$ Istituto di Statistica Medica e Biometria, Università degli Studi di Milano, Via Venezian I, 20133 Milan, Italy
}

\begin{abstract}
We investigated the role of fried foods on oral-pharyngeal and oesophageal cancers, using data from two case-control studies conducted in Italy and Switzerland between 1992 and 1999, one with a total of 749 (634 men) cases of oral/pharyngeal cancer and I772 (I 252 men) controls, the other with 395 (35I men) cases of oesophageal cancer and I 066 (875 men) controls. Controls were admitted for acute, non-neoplastic conditions, unrelated to alcohol and smoking consumption. After allowance for sex, age, centre, education, body mass index, tobacco smoking, alcohol drinking and nonalcohol energy intake, the multivariate odds ratios (ORs) for an increment of one portion per week of total fried foods were I.II (95\% confidence interval (CI): I.05- I. I7) for oral-pharyngeal and I. 16 (95\% Cl: I.08-1.26) for oesophageal cancer. The ORs were consistent across strata of gender (OR in men only were I. I0 and I.16, respectively), age, alcohol, tobacco consumption and body mass index.

British Journal of Cancer (2005) 92, 2065 -2069. doi:I0.1038/sj.bjc.6602542 www.bjcancer.com

Published online 26 April 2005

(c) 2005 Cancer Research UK
\end{abstract}

Keywords: oral neoplasms; pharyngeal neoplasms; oesophageal neoplasms; fried foods; risk factors; case-control study

Cancers of the oral cavity/pharynx and oesophagus are two of the most common cancers in the world, and their incidence and mortality rates are higher in Southern Europe than in the rest of Europe (La Vecchia et al, 2004; Levi et al, 2004). These neoplasms are strongly related to smoking and alcohol consumption (Franceschi et al, 1990; Negri et al, 1993), but several studies have related various aspects of diet to the risk of oral/pharyngeal and oesophageal cancers (Trichopoulou et al, 2000; Zheng et al, 1992). A diet rich in animal fats has been associated with an increased risk of these cancers (Launoy et al, 1998), but the epidemiological evidence on the role of meat consumption is not consistent (Franceschi et al, 1999b). A number of studies reported inverse associations with consumption of different types of meat (Launoy et al, 1998), while several other studies showed an increased risk, mainly related to barbecued and fried meat (Yu et al, 1988; De Stefani et al, 1990), suggesting that the cooking method could be involved in upper digestive tract carcinogenesis. The guidelines on diet of the American Cancer Society reported that high-temperature cooking methods (as in frying) give rise to a wide variety of mutagenic substances that are carcinogenic in experimental animals (Weinhouse et al, 1991).

Several studies have reported a direct relation between fried meat and cancers of the colon, rectum and stomach (IARC, 1993; Navarro et al, 2004). Other studies found a positive association between fried foods and laryngeal (Bosetti et al, 2002), breast (Dai et al, 2002), lung (Sinha et al, 1998), pancreatic (Anderson et al, 2002) and lower urinary tract (Steineck et al, 1990) cancers.

*Correspondence: Dr C Galeone; E-mail: galeone@marionegri.it Received I January 2005; revised 25 February 2005; accepted 25 February 2005; published online 26 April 2005
A Brazilian case-control study showed that habitual intake of bacon and fried foods was a risk factor for oral cancer (Toporcov et al, 2004). Pharyngeal cancer was also associated with a high consumption of meat and fried foods in a case-control study in Spain (Escribano Uzcudun et al, 2002).

Concerning oesophageal cancer, some studies (Yu et al, 1988; De Stefani et al, 1990) showed an increased risk, but others (Ward et al, 1997) found no association with frequent fried beef consumption.

We investigated the issue of fried meat and other fried foods using data from a large, multicentric case-control study.

\section{MATERIALS AND METHODS}

Data were obtained from two coordinated hospital-based casecontrol studies with the same design, questionnaire and inclusion criteria. In brief, the first study (Levi et al, 2000; Soler et al, 2001) was conducted between 1991 and 1997 in Italy (Pordenone, Udine, Rome, Latina) and in Switzerland and included 749 (634 men) cases of cancer of the oral cavity and pharynx (median age 57 years) and 1772 (1252 men) controls (median age 57 years) matched on age, sex and study centre. The second study (Soler et al, 2001) was conducted between 1992 and 1999 in Italy (Milan, Pordenone, Padua, Udine) and Switzerland and included 395 (351 men) cases of cancer of the oesophagus (median age 60 years) and 1066 (875 men) controls (median age 60 years) matched on age, sex and study centre. All cancer cases were incident and histologically confirmed. Controls were patients hospitalized for a wide spectrum of acute non-neoplastic conditions (overall, $23 \%$ had nonalcohol-related traumas, mostly fractures and sprains, $26 \%$ nontraumatic orthopedic disorders, $30 \%$ acute surgical conditions 
and $21 \%$ miscellaneous other illnesses such as eye, ear or skin diseases).

Cases and controls were aged $\leqslant 79$ years and were identified and questioned by trained interviewers during their hospital stay, in the same network of teaching and general hospitals in the areas under surveillance. The proportion of refusals was less than $5 \%$ in cases and controls in both studies.

Since oral-pharyngeal and oesophageal cancers are more frequent in men, and to avoid heterogeneity between sexes of the covariates included in the model, the major analyses were restricted to men and the results on female subjects were given in the text only.

The same structured questionnaire was used in both studies, including information on sociodemographic factors, anthropometric variables, smoking, alcohol and other lifestyle habits, a problem-oriented medical history, physical activity and history of cancer in relatives. Information on diet referred to the previous 2 years and was based on a validated and reproducible food frequency questionnaire (FFQ) (Franceschi et al, 1993; Decarli et al, 1996), comprising 78 foods, food groups or recipes, and allowing the estimation of total energy intake. The FFQ was divided into six section: (1) bread, cereals, first courses; (2) second courses (i.e., meat, fish and other main dishes); (3) side dishes (i.e., vegetables, fried/baked potatoes); (4) fruits; (5) sweets, desserts and soft drinks; (6) milk, hot beverages and sweeteners. At the end of each section, one or two open questions were used to include foods that were not in the questionnaire, but were eaten at least once per week. Among the items in the FFQ, some questions referred specifically to consumption of fried foods, as beef, fish, eggs and omelettes, and potatoes. It was asked for the weekly frequency of consumption of fried foods, as well as for their usual portion size. No information was obtained on the common degree of browning of fried foods.

Odds ratios (ORs), and their corresponding 95\% confidence intervals (CIs), for an increment of one portion per week of fried foods, were computed using conditional multiple logistic regression. All regression models were matched on age and study centre, and included terms for education $(<7,7-<12$, $\geqslant 12$ years), body mass index (in quintiles), alcohol consumption (in quintiles: for oral/pharyngeal cancer, cut points were $10,22.5,37.75,61$ glasses per week, and for oesophageal cancer were 8, 22.5, 35.5, 59 glasses per week, plus a term for ex-drinkers), smoking habits (never, ex, current smokers of $<15,15-<25, \geqslant 25$ cigarettes per day) and nonalcohol energy intake (in quintiles). Population attributable risks (PAR) were derived from multivariate ORs, using the method described by Bruzzi et al (1985) and Mezzetti et al (1996).

\section{RESULTS}

Table 1 shows various demographic, lifestyle and dietary characteristics among 634 male cases of oral-pharyngeal cancer and 1252 controls, and 351 male cases of oesophageal cancer and 875 controls. In both studies, cases smoked tobacco and drank alcohol much more frequently than controls. Current smokers were $71.7 \%$ of oral-pharyngeal cancer cases and $32.3 \%$ of corresponding controls, and $59.5 \%$ of oesophageal cancer cases and $32.0 \%$ of corresponding controls located. In the highest quintile of alcohol consumption were $46.6 \%$ of oral cancer cases and $8.3 \%$ of controls, and $47.0 \%$ of cases of oesophageal cancer and $10.3 \%$ of corresponding controls. Total consumption of fried foods of cases was higher than controls: the average number of portions per week of cases was 3.0 portions in both studies, as compared to 2.54 and 2.65 for controls.

In Table 2, cases and controls of the two cancers studied are distributed by level of intake of various types of fried foods. Linear trends in risk, adjusted for several potential confounding factors, assessing the difference in the distributions of the indicated types
Table I Basic demographic, life-style and dietary characteristics among 634 male cases of oral/pharyngeal cancer and I 252 male controls, and 35 I male cases of oesophageal cancer and 875 male controls, Italy and Switzerland, 1992-1999

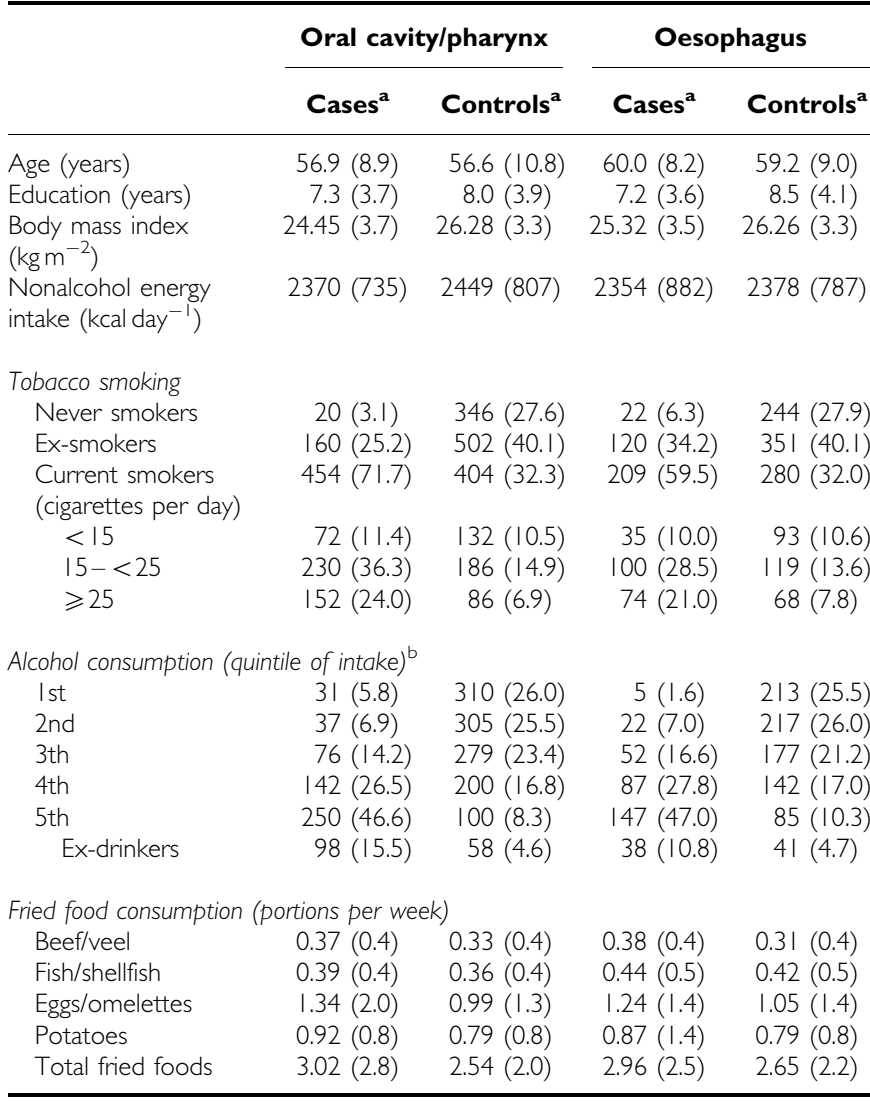

a For the quantitative variables, we present the mean value and in parentheses the standard errors, while for categorical variables we present absolute numbers and percentages in parentheses. ${ }^{b}$ Cut points for oral/pharyngeal cancer were 10, 22.5, $37.75,61$ glasses per week, and for oesophageal cancer 8, 22.5, 35.5, 59 glasses per week

of fried foods between cases and controls, are also shown. Cases reported higher intakes of fried beef, eggs and total foods, and increasing trends in risk.

Table 3 reports the ORs of oral-pharyngeal and oesophageal cancers according to different levels of intake of total fried foods, after adjustment for several potential confounding factors. The ORs of oral-pharyngeal cancer were 1.24 and 1.22 for an intake of $1-<2$ and $\geqslant 2$ portions of fried foods per week respectively, and the corresponding ORs for oesophageal cancer were 1.32 and 1.43 . The OR for an increment of one portion of fried foods per week was 1.10 (95\% CI: 1.04-1.17) for oral-pharyngeal cancer and 1.16 (95\% CI: 1.07-1.25) for oesophageal cancer. When we computed risks in women using the same regression model, the ORs for total fried foods for female subjects were substantially similar to those in men (continuous $\mathrm{OR}=1.23,95 \% \mathrm{CI}$ : $1.06-1.42$ for oral and pharyngeal cancers and $\mathrm{OR}=1.14,95 \% \mathrm{CI}$ : $0.83-1.55$ for oesophageal cancer), and for men and women combined the ORs were 1.11 and 1.16 , respectively.

In Table 4 are considered the continuous ORs according to total fried foods consumption, in separate strata of age, alcohol drinking, tobacco smoking and body mass index. No significant heterogeneity emerged across any of the strata considered $(P$-values not shown). 
Table 2 Distribution of 634 male cases and 1252 male controls of oral/ pharyngeal cancer, and $35 \mathrm{I}$ male cases and 875 male controls of oesophageal cancer, according to fried food consumption, Italy and Switzerland, 1992-1999

\begin{tabular}{|c|c|c|c|c|}
\hline \multirow{2}{*}{$\begin{array}{l}\text { Fried food } \\
\text { (servings per } \\
\text { week) }\end{array}$} & \multicolumn{3}{|c|}{ Level of intake } & \multirow[b]{2}{*}{$Z^{a, b}$ for trend } \\
\hline & I (lowest) & 2 & 3 (highest) & \\
\hline & \multicolumn{3}{|c|}{ Oral cavity/pharynx } & \\
\hline \multicolumn{5}{|l|}{ Beeflveal $^{c}$} \\
\hline Cases & 365 & 169 & 100 & 0.65 \\
\hline Controls & 739 & 336 & 177 & \\
\hline \multicolumn{5}{|l|}{ Fish/shellfish ${ }^{c}$} \\
\hline Cases & 311 & 223 & 100 & 1.26 \\
\hline Controls & 677 & 358 & 217 & \\
\hline \multicolumn{5}{|l|}{ Egos/omelettes ${ }^{c}$} \\
\hline Cases & 186 & 120 & 328 & 2.70 \\
\hline Controls & 449 & 268 & 535 & \\
\hline \multicolumn{5}{|l|}{ Potatoes $^{c}$} \\
\hline Cases & 184 & 151 & 299 & 0.01 \\
\hline Controls & 390 & 312 & 550 & \\
\hline \multicolumn{5}{|l|}{ Total fried foods ${ }^{\mathrm{d}}$} \\
\hline Cases & 96 & 143 & 395 & 0.90 \\
\hline Controls & 231 & 294 & 727 & \\
\hline \multicolumn{5}{|c|}{ Oesophagus } \\
\hline \multicolumn{5}{|l|}{ Beef/ veal ${ }^{\mathrm{c}}$} \\
\hline Cases & 184 & 127 & 40 & 1.94 \\
\hline Controls & 535 & 235 & 105 & \\
\hline \multicolumn{5}{|l|}{ Fish/shellfish ${ }^{c}$} \\
\hline Cases & 166 & 133 & 52 & -0.20 \\
\hline Controls & 429 & 281 & 165 & \\
\hline \multicolumn{5}{|l|}{ Eggs/omelettes ${ }^{c}$} \\
\hline Cases & 88 & 107 & 156 & 2.69 \\
\hline Controls & 276 & 234 & 365 & \\
\hline \multicolumn{5}{|l|}{ Potatoes $^{c}$} \\
\hline Cases & 121 & 109 & 121 & -0.14 \\
\hline Controls & 283 & 236 & 356 & \\
\hline \multicolumn{5}{|l|}{ Total fried foods ${ }^{\mathrm{d}}$} \\
\hline Cases & 60 & 94 & 197 & 1.49 \\
\hline Controls & 175 & 212 & 488 & \\
\hline
\end{tabular}

aEstimates from conditional logistic regression conditioned on age, centre, and adjusted for education, body mass index, tobacco smoking, alcohol drinking and nonalcohol energy intake. ${ }^{b} Z$ values are interpretable as standard normal deviates. 'The first level of intake was less then 0.5 portion per week, the second level was $0.5-<$ I portion per week, the third level was $\geqslant 1$ portion per week. ${ }^{\mathrm{d}}$ The first level of intake was less then I portion per week, the second level was $\mid-<2$ portions per week, the third level was $\geqslant 2$ portions per week.

\section{DISCUSSION}

This study found that a diet rich in fried foods was related to a moderate increase in risk of upper aero-digestive tract cancers in men. These findings follow a recent companion study from Bosetti et al (2002), which found that consumption of fried foods was directly associated to laryngeal cancer risk. The observed risk may be explained by a direct action of carcinogens produced by frying, and is plausible since there is a direct combination between these substances and the upper respiratory tract. In fact, during the frying of protein-rich food, such as meat and fish, genotoxic
Table 3 Odds ratios (OR) and corresponding 95\% confidence intervals (Cls) according to total fried food consumption among 634 male cases and I 252 male controls of oral/pharyngeal cancer, and 35 I male cases and 875 male controls of oesophageal cancer, Italy and Switzerland, 1992-1999

\begin{tabular}{|c|c|c|c|c|}
\hline \multirow[b]{2}{*}{ Total fried foods } & \multicolumn{3}{|c|}{ Level of intake (portions per week) } & \multirow[b]{2}{*}{ Continuous $\mathrm{OR}^{\mathrm{c}}$} \\
\hline & $\mid s<1$ & $1-<2$ & $\geqslant 2$ & \\
\hline $\begin{array}{c}\text { Oral cavity/phanynx } \\
\operatorname{OR}^{\mathrm{a}}(95 \% \mathrm{Cl})\end{array}$ & $1^{\mathrm{b}}$ & $1.24(0.83-1.85)$ & $1.22(0.85-1.74)$ & $1.10(1.04-1.17)$ \\
\hline $\begin{array}{l}\text { Oesophagus } \\
\operatorname{OR}^{\mathrm{a}}(95 \% \mathrm{Cl})\end{array}$ & $1^{\mathrm{b}}$ & $1.32(0.83-2.12)$ & $1.43(0.92-2.24)$ & $1.16(1.07-1.25)$ \\
\hline
\end{tabular}

astimates from conditional logistic regression conditioned on age, centre, and adjusted for education, body mass index, tobacco smoking, alcohol drinking and nonalcohol energy intake. ${ }^{b}$ Reference category. ${ }^{c}$ For an increment of one portion per week

heterocyclic amines (HCAs) are formed (Pfau and Marquardt, 2001). The most important variables contributing to the formation of HCAs are: cooking temperature $\left(>150^{\circ} \mathrm{C}\right)$, cooking time ( $>2 \mathrm{~min}$ ) and cooking method (frying, oven grilling/broiling, barbecuing) (Thomson, 1999). Heterocyclic amine compounds formed in the cooking of certain foods have been shown to be bacterial mutagens and animal carcinogens. In rats, these amines induce cancer specifically in sites such as breast, colon or pancreas, which are associated with Western-type diet, where promotional elements such as dietary fat play an enhancing role (Weisburger and Jones, 1990).

However, other factors, besides HCA, could give explanation to the positive association observed between fried foods and these neoplasms. Some studies found that a diet rich in meat and eggs, independently from the cooking methods, lead to an increased risk of oral and oesophageal cancers (Franceschi et al, 1999a; Bosetti et al, 2000). Also, a possible explanation of the increased risks may be linked to the fat used for frying. In fact, in Italy, eggs, which presented the strongest direct associations with cancer risk in both of these studies, and beef are frequently fried using butter, whose detrimental effect on upper aero-digestive tract cancers was found in several studies (Launoy et al, 1998; Franceschi et al, 1999a; Bosetti et al, 2002). However, fish and potatoes are usually fried in oils, mostly olive oil and specific or mixed seeds oil, and it was found that these types of oils were protective for oral/pharyngeal and esophageal cancers (Franceschi et al, 1999a; Bosetti et al, 2000).

In order to reduce potential information bias, in this study the questionnaire was administered to both cases and controls by the same interviewers, under similar conditions, and controls were selected among patients with admission diagnosis not related to tobacco smoking, alcohol drinking and diet modifications. Bias in the recall of food intake should be limited in this not particularly health conscious population, and given the comparability between cases and controls in hospital-based settings (D'Avanzo et al, 1997). The high participation rate of cases and controls, the comparable catchment areas of study subjects, the careful adjustment for tobacco and alcohol, as well as for other potential confounding factors, are among the strengths of the study. Moreover, the use of a substantially reproducible and valid questionnaire (Franceschi et al, 1993; Decarli et al, 1996) allowed to take into account the full dietary pattern and to adjust for total energy intake (Willett and Stampfer, 1986; Franceschi et al, 1999b).

Nevertheless, the increase in risk was moderate and bias or confounding may account at least for part of it. Fried food 
Table 4 Odds ratios (ORs) and corresponding 95\% confidence intervals (Cls) according to fried food consumption in strata of selected covariates among 634 male cases and 1252 male controls of oral/pharyngeal cancer, and 35 I male cases and 875 male controls of oesophageal cancer, Italy and Switzerland, $1992-1999$

\begin{tabular}{|c|c|c|c|c|c|c|c|c|}
\hline & \multicolumn{8}{|c|}{$O^{a}(95 \% \mathrm{Cl})$} \\
\hline \multicolumn{9}{|l|}{ Oral cavity/pharynx } \\
\hline Total fried foods & $\begin{array}{l}1.13 \\
(1.03-1.23)\end{array}$ & $\begin{array}{l}1.08 \\
(0.99-1.18)\end{array}$ & $\begin{array}{l}1.02 \\
(0.92-1.14)\end{array}$ & $\begin{array}{l}1.16 \\
(1.06-1.26)\end{array}$ & $\begin{array}{l}1.00 \\
(0.83-1.20)\end{array}$ & $\begin{array}{l}1.13 \\
(1.06-1.22)\end{array}$ & $\begin{array}{l}1.12 \\
(1.03-1.23)\end{array}$ & $\begin{array}{l}1.09 \\
(1.00-1.19)\end{array}$ \\
\hline \multicolumn{9}{|l|}{ Oesophagus } \\
\hline Total fried foods & $\begin{array}{l}1.24 \\
(1.09-1.42)\end{array}$ & $\begin{array}{l}1.13 \\
(1.02-1.27)\end{array}$ & $\begin{array}{l}1.14 \\
(0.98-1.32)\end{array}$ & $\begin{array}{l}1.17 \\
(1.06-1.30)\end{array}$ & $\begin{array}{l}1.16 \\
(0.95-1.43)\end{array}$ & $\begin{array}{l}1.17 \\
(1.07-1.27)\end{array}$ & $\begin{array}{l}1.14 \\
(1.01-1.28)\end{array}$ & $\begin{array}{l}1.19 \\
(1.06-1.34)\end{array}$ \\
\hline
\end{tabular}

${ }^{a}$ For an increase of one serving per week; estimates from conditional logistic regression conditioned on age and study centre, and adjusted for education, body mass index, tobacco smoking, alcohol drinking and nonalcohol energy intake. 'Median value for oral/pharyngeal cancer was 31 glasses per week, for oesophageal cancer 29.75 glasses per week. Including never smokers and ex-smokers since 20 or more years. ${ }^{~ I n c l u d i n g ~ s m o k e r s ~ a n d ~ e x-s m o k e r s ~ s i n c e ~ l e s s ~ t h a n ~} 20$ years.

consumption may simply be an indicator of a generally less healthy lifestyle (Utter et al, 2003), although we carefully controlled in the regression models for education and/or lifestyle covariates including tobacco and alcohol consumption. If the associations are real, the adjusted PARs for fried foods in men would be $14 \%$ (95\% CI: $0-37.9 \%)$ for oral/pharyngeal cancers and $21 \%(95 \% \mathrm{CI}$ : $0-47.6 \%)$ for esophageal cancer, further confirming the importance of diet in the aetiology of these neoplasms (Negri et al, 1993).

\section{ACKNOWLEDGEMENTS}

This work was conducted with the contribution of the Italian Association forCancer Research, the Italian and Swiss Leagues against Cancer, the Swiss Research against Cancer (KFS 700) and the Italian Ministry of Education (COFIN 2003). We thank Mrs C Pasche and F Lucchini for Swiss data collection and validation, and Mrs I Garimoldi for editorial assistance.

\section{REFERENCES}

Anderson KE, Sinha R, Kulldorff M, Gross M, Lang NP, Barber C, Harnack L, DiMagno E, Bliss R, Kadlubar FF (2002) Meat intake and cooking techniques: associations with pancreatic cancer. Mutat Res 506-507: $225-231$

Bosetti C, La Vecchia C, Talamini R, Simonato L, Zambon P, Negri E, Trichopoulos D, Lagiou P, Bardini R, Franceschi S (2000) Food groups and risk of squamous cell esophageal cancer in northern Italy. Int $J$ Cancer 87(2): 289-294

Bosetti C, Talamini R, Levi F, Negri E, Franceschi S, Airoldi L, La Vecchia C (2002) Fried foods: a risk factor for laryngeal cancer? Br J Cancer 87(11): $1230-1233$

Bruzzi P, Green SB, Byar DP, Brinton LA, Schairer C (1985) Estimating the population attributable risk for multiple risk factors using case-control data. Am I Epidemiol 122: 904-914

D’Avanzo B, La Vecchia C, Katsouyanni K, Negri E, Trichopoulos D (1997) An assessment, and reproducibility of food frequency data provided by hospital controls. Eur J Cancer Prev 6(3): 288-293

Dai Q, Shu XO, Jin F, Gao YT, Ruan ZX, Zheng W (2002) Consumption of animal foods, cooking methods, and risk of breast cancer. Cancer Epidemiol Biomarkers Prev 11(9): $801-808$

Decarli A, Franceschi S, Ferraroni M, Gnagnarella P, Parpinel MT, La Vecchia C, Negri E, Salvini S, Falcini F, Giacosa A (1996) Validation of a food-frequency questionnaire to assess dietary intakes in cancer studies in Italy. Results for specific nutrients. Ann Epidemiol 6: 110-118

De Stefani E, Munoz N, Esteve J, Vasallo A, Victora CG, Teuchmann S (1990) Mate drinking, alcohol, tobacco, diet, and esophageal cancer in Uruguay. Cancer Res 50(2): 426-431

Escribano Uzcudun A, Rabanal Retolaza I, Garcia Grande A, Miralles Olivar L, Garcia Garcia A, Gonzalez Baron M, Gavilan Bouzas J (2002) Pharyngeal cancer prevention: evidence from a case-control study involving 232 consecutive patients. J Laryngol Otol 116(7): 523 - 531

Franceschi S, Barbone F, Negri E, Decarli A, Ferraroni M, Filiberti R, Giocosa G, Gnagnarella P, Nanni O, Salvini S, La Vecchia C (1993) Reproducibility of an Italian food frequency questionnaire for cancer studies: results for specific food items. Eur J Cancer 29A: 2298-2305
Franceschi S, Favero A, Conti E, Talamini R, Volpe R, Negri E, Barzan L, La Vecchia C (1999a) Food groups, oils and butter, and cancer of the oral cavity and pharynx. Br J Cancer 80(3-4): 614-620

Franceschi S, Levi F, Conti E, Talamini R, Negri E, Dal Maso L, Boyle P, Decarli A, La Vecchia C (1999b) Energy intake and dietary pattern in cancer of the oral cavity and pharynx. Cancer Causes Control 10(5): 439 444

Franceschi S, Talamini R, Barra S, Baron AE, Negri E, Bidoli E, Serraino D, La Vecchia C (1990) Smoking and drinking in relation to cancers of the oral cavity, pharynx, larynx, and esophagus in northern Italy. Cancer Res 50(20): $6502-6507$

IARC, International Agency for Research on Cancer (1993) Some naturally occurring substances: food items and constituents, heterocyclic aromatics amines and mycotoxins. IARC Monographs on the Evaluation of Carcinogenic Risks to Human 56. Lyon, France: IARC

Launoy G, Milan C, Day NE, Pienkowski MP, Gignoux M, Faivre J (1998) Diet and squamous-cell cancer of the oesophagus: a French multicentre case-control study. Int J Cancer 76(1): 7-12

La Vecchia C, Lucchini F, Negri E, Levi F (2004) Trends in oral cancer mortality in Europe. Oral Oncol 40(4): 433-439

Levi F, Lucchini F, Negri E, Boyle P, La Vecchia C (2004) Cancer mortality in Europe, 1995-1999, and an overview of trends since 1960. Int J Cancer 110(2): 155-169, Erratum in: Int J Cancer 111(6): 981

Levi F, Pasche C, Lucchini F, Chatenoud L, Jacobs Jr DR, La Vecchia C (2000) Refined and whole grain cereals and the risk of oral, oesophageal and laryngeal cancer. Eur J Clin Nutr 54: 487-489

Mezzetti M, Ferraroni M, Decarli A, La Vecchia C, Benichou J (1996) Software for attributable risk and confidence interval estimation in case-control studies. Comput Biomed Res 29: 63-75

Navarro A, Munoz SE, Lantieri MJ, Del Pilar Diaz M, Cristaldo PE, de Fabro SP, Eynard AR (2004) Meat cooking habits and risk of colorectal cancer in Cordoba, Argentina. Nutrition 20(10): 873-877

Negri E, La Vecchia C, Franceschi S, Tavani A (1993) Attributable risk for oral cancer in northern Italy. Cancer Epidemiol Biomarkers Prev 2(3): 189- 193 
Pfau W, Marquardt H (2001) Cell transformation in vitro by food-derived heterocyclic amines Trp-P-1, Trp-P-2 and N(2)-OH-PhIP. Toxicology 166(1-2): $25-30$, Review

Sinha R, Kulldorff M, Curtin J, Brown CC, Alavanja MC, Swanson CA (1998) Fried, well-done red meat and risk of lung cancer in women (United States). Cancer Causes Control 9(6): 621-630

Soler M, Bosetti C, Franceschi S, Negri E, Zambon P, Talamini R, Conti E, La Vecchia C (2001) Fiber intake and the risk of oral, pharyngeal and esophageal cancer. Int J Cancer 91: 283-287

Steineck G, Hagman U, Gerhardsson M, Norell SE (1990) Vitamin A supplements, fried foods, fat and urothelial cancer. A case-referent study in Stockholm in 1985-1987. Int J Cancer 45(6): $1006-1011$

Thomson B (1999) Heterocyclic amine levels in cooked meat and the implication for New Zealanders. Eur J Cancer Prev 8(3): 201-206

Toporcov TN, Antunes JL, Tavares MR (2004) Fat food habitual intake and risk of oral cancer. Oral Oncol 40(9): 925-931

Trichopoulou A, Lagiou P, Kuper H, Trichopoulos D (2000) Cancer and Mediterranean dietary traditions. Cancer Epidemiol Biomarkers Prev 9(9): $869-873$, Review

Utter J, Neumark-Sztainer D, Jeffery R, Story M (2003) Couch potatoes or French fries: are sedentary behaviors associated with body mass index, physical activity, and dietary behaviors among adolescents? J Am Diet Assoc 103(10): $1298-1305$

Ward MH, Sinha R, Heineman EF, Rothman N, Markin R, Weisenburger DD, Correa P, Zahm SH (1997) Risk of adenocarcinoma of the stomach and esophagus with meat cooking method and doneness preference. Int $J$ Cancer 71(1): $14-19$

Weinhouse S, Bal DG, Adamson R, Dwyer J, Kleinman RE, Kritchevsky D, Mettlin CJ, Newell GR, Rivlin R, Wattenberg L (1991) American Cancer Society guidelines on diet, nutrition, and cancer. The Work Study Group on diet, nutrition, and cancer. CA Cancer J Clin 41(6): 334-338

Weisburger JH, Jones RC (1990) Prevention of formation of important mutagens/carcinogens in the human food chain. Basic Life Sci 52: 105-118, Review

Willett W, Stampfer MJ (1986) Total energy intake: implications for epidemiologic analyses. Am J Epidemiol 124(1): 17-27, Review

Yu MC, Garabrant DH, Peters JM, Mack TM (1988) Tobacco, alcohol, diet, occupation, and carcinoma of the esophagus. Cancer Res 48(13): $3843-3848$

Zheng W, Blot WJ, Shu XO, Diamond EL, Gao YT, Ji BT, Fraumeni Jr JF (1992) Risk factors for oral and pharyngeal cancer in Shanghai, with emphasis on diet. Cancer Epidemiol Biomarkers Prev 1(6): 441-448 